Supporting Information for:

\title{
Fitting Neurological Protein Aggregation Kinetic Data via a 2-Step, Minimal / "Ockham's Razor" Model: the Finke-Watzky Mechanism of Nucleation Followed by Autocatalytic Surface Growth
}

\footnotetext{
Aimee M. Morris, ${ }^{\ddagger}$ Murielle A. Watzky ${ }^{\ddagger}$ Jeffrey N. Agar, ${ }^{\S}$ and Richard G. Finke ${ }^{\ddagger} *$

${ }^{\ddagger}$ Department of Chemistry, Colorado State University, Fort Collins, CO 80523, USA

${ }^{\S}$ Department of Chemistry and Volen Center, Brandeis University, 415 South Street, Waltham, Massachusetts 02454, USA
}

*Corresponding author: rfinke@ lamar.colostate.edu 
Scheme S1. The derivation of the analytic equation for the F-W mechanism. This derivation in the original reference (i) contains typesetting errors that were not caught at the time of publication and should read:

$$
\begin{aligned}
& -\frac{d[A]}{d t}=k_{1}[A]+k_{2}[A]\left([A]_{0}-[A]\right) \\
& \int_{0}^{t} \frac{-d[A]}{[A]\left(k_{1}+k_{2}\left([A]_{0}-[A]\right)\right)}=\int_{0}^{t} d t \\
& \frac{1}{k_{1}+k_{2}[A]_{0}} * \ln \left[\frac{k_{1}+k_{2}\left([A]_{0}-[A]\right)}{[A]}\right]_{0}^{t}=t \\
& \ln \left[\frac{\left(k_{1}+k_{2}\left([A]_{0}-[A]\right)\right)[A]_{0}}{k_{1}[A]}\right]=\left(k_{1}+k_{2}[A]_{0}\right) t
\end{aligned}
$$


Scheme S2. Derivation showing the equivalence of the Finke-Watzky (F-W) 2-step mechanism to Saitô and coworkers' (ii) 3-step mechanism for the aggregation of calcitonin.

Saitô's equation :

$f=\frac{\rho\left(e^{(1+\rho) k t}-1\right)}{1+\rho e^{(1+\rho) k t}}$

By definition :

$\rho=\frac{k_{1}}{k}, k=k_{2} a, a=[A]_{0}$,

Substitution gives :

$$
f=\frac{\frac{k_{1}}{k_{2}[A]_{0}}\left(e^{\left(1+\frac{k_{1}}{\left.k_{2} A\right]_{0}}\right) k_{2}[A]_{0} t}-1\right)}{1+\frac{k_{1}}{k_{2}[A]} e^{\left.\left(1+\frac{k_{1}}{k_{2}[A]_{0}}\right) k_{2}[A]\right]_{0} t}}
$$

Simplifying :

$$
f=\frac{\frac{k_{1}}{k_{2}[A]_{0}}\left(e^{\left(k_{1}+k_{2}[A]_{0}\right) t}-1\right)}{1+\frac{k_{1}}{k_{2}[A]_{0}} e^{\left(k_{1}+k_{2}[A]_{0}\right) t}}
$$

By definition :

$[A]_{t}=[A]_{0}(1-f) \Rightarrow f=1-\frac{[A]_{t}}{[A]_{0}}$

Substituting for $\mathrm{f}$ gives :

$1-\frac{[A]_{t}}{[A]_{0}}=\frac{\frac{k_{1}}{k_{2}[A]_{0}}\left(e^{\left(k_{1}+k_{2}[A]_{0}\right) t}-1\right)}{1+\frac{k_{1}}{k_{2}[A]_{0}} e^{\left(k_{1}+k_{2}[A]_{0}\right) t}}$

Solving for $[\mathrm{A}]_{\mathrm{t}}$ :

$[A]_{t}=[A]_{0}\left(1-\frac{\frac{k_{1}}{k_{2}[A]_{0}}\left(e^{\left(k_{1}+k_{2}[A]_{0}\right) t}-1\right)}{1+\frac{k_{1}}{k_{2}[A]_{0}} e^{\left(k_{1}+k_{2}[A]_{0}\right) t}}\right)$

Simplification gives :

$[\mathrm{A}]_{\mathrm{t}}=\frac{\frac{k_{1}}{k_{2}}+[A]_{0}}{1+\frac{k_{1}}{k_{2}[A]_{0}} e^{\left(k_{1}+k_{2}[A]_{0}\right) t}}$

This last equation is the Finke - Watzky analytic equation corresponding to the 2 - step mechanism. 
Scheme S3. Comparison of the Original and Generalized Form of the F-W 2-Step Mechanism.

The original form of the equation is

$$
\begin{aligned}
& \mathrm{A} \stackrel{\mathrm{k}_{1}}{\longrightarrow} \mathrm{B} \\
& \mathrm{A}+\mathrm{B} \stackrel{\mathrm{k}_{2}}{\longrightarrow} 2 \mathrm{~B}
\end{aligned}
$$

where the sum reaction is

$$
2 \mathrm{~A} \rightarrow 2 \mathrm{~B}
$$

which gives the rate equation:

$\frac{-d[A]}{d t}=k_{1}[A]+k_{2}[A][B]$

Whereas the generalized form of the 2-step mechanism is given by

$$
\begin{aligned}
& \mathrm{nA} \stackrel{\mathrm{k}_{1}^{\prime}}{\longrightarrow} \mathrm{B}_{\mathrm{n}} \\
& \mathrm{A}+\mathrm{B}_{\mathrm{n}} \stackrel{\mathrm{k}_{2}^{\prime}}{\longrightarrow} \mathrm{B}_{\mathrm{n}+1}
\end{aligned}
$$

where the sum reaction is

$$
(\mathrm{n}+1) \mathrm{A} \rightarrow \mathrm{B}_{\mathrm{n}+1}
$$

which gives the rate equation:

$$
\frac{\frac{-d[A]}{d t}}{(n+1)}=k_{1}^{\prime}[A]^{n}+k_{2}^{\prime}[A]\left[B_{n}\right]
$$

At constant $[\mathrm{A}]$ (during nucleation), and with the zeroth-order approximation that one can equate $[\mathrm{B}]$ with $\left[\mathrm{B}_{\mathrm{n}}\right]$ (i.e., by treating $\mathrm{B}$ as one species), then $\mathrm{k}_{1} \mathrm{vs} \mathrm{k}_{1}{ }^{\prime}$ and $\mathrm{k}_{2} \mathrm{vs}_{2}{ }^{\prime}$ are related by

$$
\begin{aligned}
& k_{1} \approx(n+1) k_{1}^{\prime}[A]^{n-1} \\
& k_{2} \approx(n+1) k_{2}^{\prime}
\end{aligned}
$$

Hence, there is just a statistical factor difference of $(n+1)$ between the $k_{2}$ and $k_{2}$ ' rate constants and a similar $(\mathrm{n}+1)$ factor, as well as a multiplicative $[\mathrm{A}]^{\mathrm{n}-1}$ concentration factor, between the $\mathrm{k}_{1}$ and $\mathrm{k}_{1}{ }^{\prime}$ rate constants. 
Scheme S4. Examination of the Scaling Factors for the Rate Constants, $\mathrm{k}_{1}$ and $\mathrm{k}_{2}$.

Beginning with the generalized form of the 2-step mechanism

$$
\begin{aligned}
& \mathrm{nA} \stackrel{\mathrm{k}_{1}^{\prime}}{\longrightarrow} \mathrm{B}_{\mathrm{n}} \\
& \mathrm{A}+\mathrm{B}_{\mathrm{n}} \stackrel{\mathrm{k}_{2}^{\prime}}{\longrightarrow} \mathrm{B}_{\mathrm{n}+1}
\end{aligned}
$$

where the sum reaction is

$$
(\mathrm{n}+1) \mathrm{A} \rightarrow \mathrm{B}_{\mathrm{n}+1}
$$

There are several factors suggested to increase the aggregation but for argument sake, if you assume only one factor contributes to aggregation and apply Fink's (iii) definition of B to be a partially folded intermediate which has aggregative (i.e., hydrophobic, charged or other (iv)) patches for increased fibrillation, then the following can be obtained:

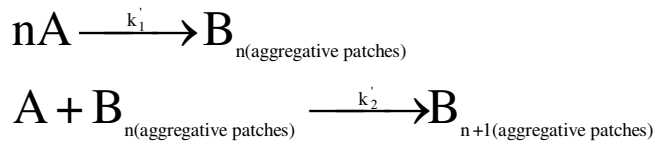

In a zeroth-order treatment that mirrors our earlier one for transition-metal nanoclusters (i), we define $\chi_{\text {(nucleation or growth) }}$ as the fraction of increased area of aggregative patches gained in a reaction step of nucleation or growth:

$\chi_{\text {(nucleation o r rowuth }}=\frac{\text { increase in area of aggregative patche }}{\text { total area of aggregative patches }}$

The generalized form can be rewritten then for protein aggregation as:

$$
\begin{aligned}
& \mathrm{A} \stackrel{\mathrm{k}_{1}^{\tilde{O}}}{\longrightarrow} \mathrm{B}_{\chi_{\text {nucleation }}} \\
& \mathrm{A}+\mathrm{B}_{\chi_{\text {nucleation }}} \stackrel{\mathrm{k}_{2}^{\tilde{\mathrm{O}}}}{\longrightarrow} \mathrm{B}\left(\chi_{\text {nucleation }}+\chi_{\text {growth }}\right)
\end{aligned}
$$

where the sum reaction is

$2 \mathrm{~A} \rightarrow \mathrm{B}_{\left(\chi_{\text {nucleation }}+\chi_{\text {growth }}\right)}$ 
If you assume that B is needed in order to form aggregative patches then (as before (i)) a reasonable assumption is that $\chi_{\text {nucleation }} \approx 1$ which gives:

$$
2 \mathrm{~A} \rightarrow \mathrm{B}_{\left(1+\chi_{\text {growh }}\right)}
$$

or rewritten

$$
2 \mathrm{~A} \rightarrow\left(1+\chi_{\text {growth }}\right) \mathrm{B}
$$

since there are $\left(1+\chi_{\text {growth }}\right)$ number of aggregative patches in this given example. From this we obtain:

$$
\begin{aligned}
& -\frac{1}{2} \frac{d[A]}{d t}=\frac{1}{1+\chi_{\text {growth }}} \frac{d[B]}{d t} \\
& \frac{d[B]}{d t}=-\frac{1+\chi_{\text {growth }}}{2} \frac{d[A]}{d t} \\
& {[B]_{t}=\frac{1+\chi_{\text {growth }}}{2}\left([A]_{0}-[A]_{t}\right)}
\end{aligned}
$$

so the rate equation becomes

$$
\begin{aligned}
& -\frac{d[A]}{d t}=k_{1}[A]+k_{2}[A][B] \\
& -\frac{d[A]}{d t}=k_{1}[A]+k_{2} \frac{1+\chi_{\text {growth }}}{2}[A]\left([A]_{0}-[A]_{t}\right)
\end{aligned}
$$

Therefore, the value of $\mathrm{k}_{2}$ has a scaling factor of $\left(1+\chi_{\text {growth }}\right) / 2$. 
For an expanded list of nanocluster formation references in which the F-W mechanism has been demonstrated to account for the kinetic data, see references i,v,vi,vii,viii,ix.

For other selected key references on fibril intermediates which includes soluble oligomers and protofibrils for which there was not space in the main text, please refer to references $\mathrm{x}, \mathrm{xi}, \mathrm{xii}, \mathrm{xiii}, \mathrm{xiv}$ below.

Figure S1 below shown the data for the uncorrected amyloid $\beta$ aggregation from Lynn and coworkers' 2006 report (xv) along with the fits to the F-W 2-step mechanism. These data were corrected in Figure 5 of the main text using the assumption that, if a blank of the sample were run, then the negative ellipticity values observed would have been negative throughout the measurement. The raw data is also provided below in Table S1, along with the rate constants and correlations for the fits from both the uncorrected and corrected data, so that the interested reader can compare the fits for themselves.

(a)

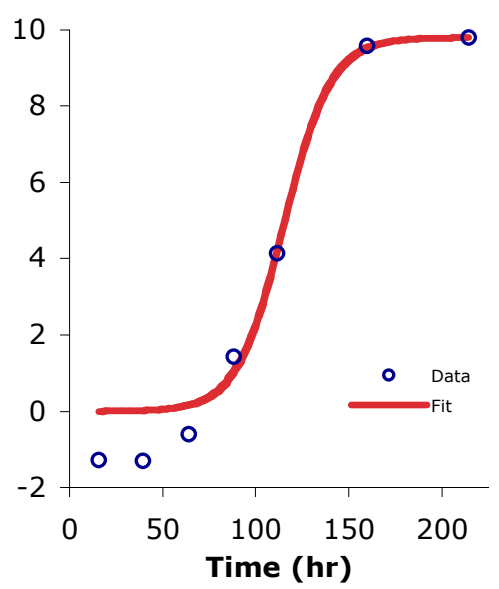

(b)

(c)
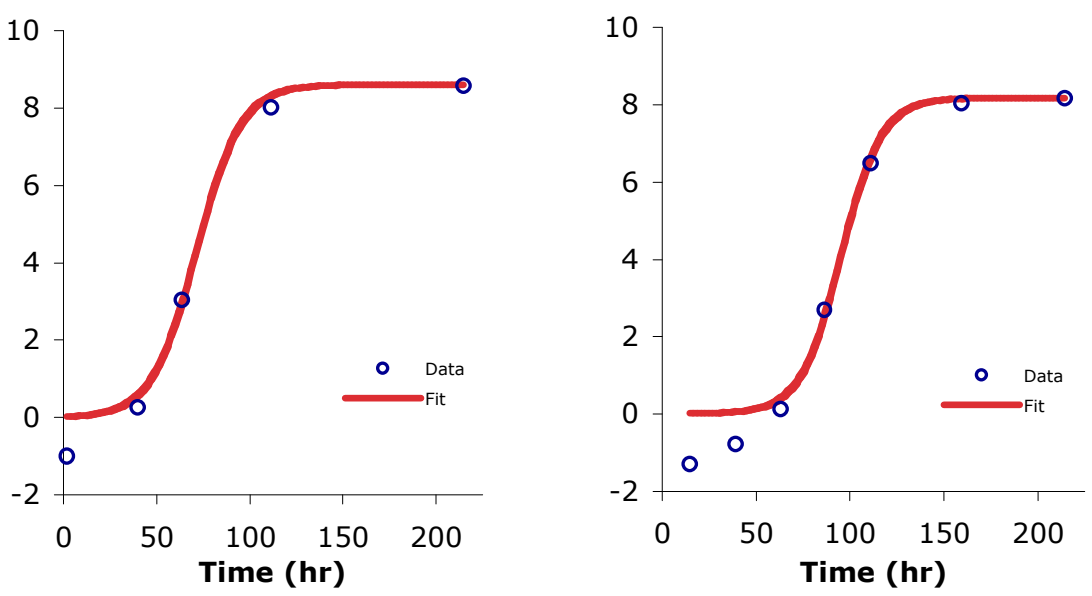
Figure S1. Digitized data of Lynn and coworkers' (xv) amyloid $\beta$ peptide measured as a function of added $\mathrm{Zn}^{2+}$ and fit to the F-W 2-step mechanism. The authors speculate that $\mathrm{Zn}^{2+}$ binding sites exist along the $\beta$ sheets of amyloid $\beta$ peptides; therefore, they measured the aggregation as a function of added $\left[\mathrm{Zn}^{2+}\right]$ and observed a reduced nucleation time with increased $\left[\mathrm{Zn}^{2+}\right]$. Figure (a) is for $1 \mathrm{mM}$ of the peptide alone with $\mathrm{k}_{1}=1(3) \times 10^{-5} \mathrm{hr}^{-1}$ and $\mathrm{k}_{2}=8(4) \times 10^{-3} \mathrm{mM}^{-1} \cdot \mathrm{hr}^{-1}$, (b) is for $\left[\mathrm{Zn}^{2+}\right]$ :[peptide] of 0.2 with $\mathrm{k}_{1}=2(4) \times 10^{-4} \mathrm{hr}^{-1}$ and $\mathrm{k}_{2}=1.0(4) \times 10^{-3} \mathrm{mM}^{-1} \bullet \mathrm{hr}^{-1}$, and (c) represents a [ $\left.\mathrm{Zn}^{2+}\right]:[$ peptide] of 0.4 with $\mathrm{k}_{1}=1(3) \times 10^{-5} \mathrm{hr}^{-1}$ and $\mathrm{k}_{2}=1.1(2) \times 10^{-2} \mathrm{mM}^{-1} \cdot \mathrm{hr}^{-1}$. The induction periods are less well fit in this data set vs the fits shown in Figure 5 of the main text.

Table S1. Comparison of the rate constants and coefficient of determination for the uncorrected and corrected data from Lynn's (xv) amyloid $\beta$ aggregation system measured by circular dichroism.

\begin{tabular}{lcrrr}
\hline & $\begin{array}{c}\text { Data } \\
\text { Corrected? }\end{array}$ & \multicolumn{1}{c}{$\mathrm{k}_{1}\left(\mathrm{hr}^{-1}\right)$} & $\mathrm{k}_{2}\left(\mathrm{mM}^{-1} \mathrm{hr}^{-1}\right)$ & $\mathrm{R}^{2}$ \\
\hline 1 mM peptide & No & $1(3) \times 10^{-5}$ & $8(4) \times 10^{-3}$ & 0.9707 \\
& Yes & $1.0(5) \times 10^{-4}$ & $5.1(5) \times 10^{-3}$ & 0.9973 \\
& No & $2(4) \times 10^{-4}$ & $1.0(4) \times 10^{-3}$ & 0.9839 \\
{$[\mathrm{Zn}]:[$ peptide] $=0.2$} & Yes & $8.3(3) \times 10^{-4}$ & $6.55(9) \times 10^{-3}$ & 1.0000 \\
& No & $1(3) \times 10^{-5}$ & $1.1(3) \times 10^{-2}$ & 0.9762 \\
{$[\mathrm{Zn}]:[$ peptide] $=0.4$} & Yes & $1.6(4) \times 10^{-4}$ & $7.1(4) \times 10^{-3}$ & 0.9988 \\
& & & & \\
& & & & \\
& & &
\end{tabular}

Effect of Added $\left[\mathrm{Zn}^{2+}\right]$ to the Rate Constants of Amyloid $\beta$ Aggregation. From the fits shown in Figure 5a-c of the main text, the effects on $\mathrm{k}_{1}$ and $\mathrm{k}_{2}$ of $0,0.2$, and $0.4 \mathrm{mM}$ added $\mathrm{Zn}^{2+}$ were examined, Figure S2. The results in Figure S2 show that there is no clean trend in the $\mathrm{k}_{1}$ values, and little effect within what is probably the true experimental error on the $\mathrm{k}_{2}$ values, at least within the range tested of $0-0.4 \mathrm{mM}$ added $\mathrm{Zn}^{2+}$. 
(a)

(b)

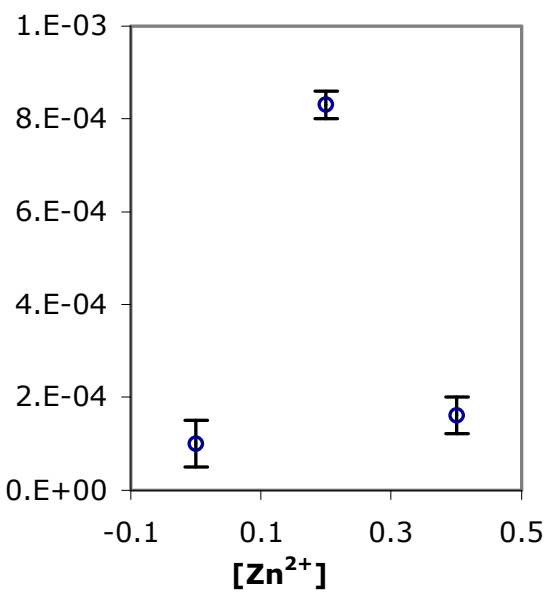

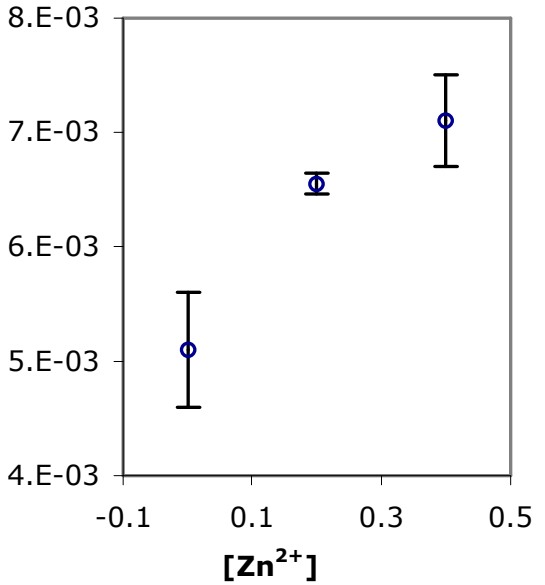

Figure S2. The effect of added $\mathrm{Zn}^{2+}$ of Lynn's (xv) amyloid $\beta$ aggregation on the (a) $\mathrm{k}_{1}$ and (b) $k_{2}$ values obtained from the corrected data in Figure 5 of the main text.

Data Analysis and Curve Fitting Following the Loss of [A]. Data were extracted from published kinetic curves using Engauge Digitizer 2.12. In the cases presented below, the y-axis was inverted vs. that presented in the main text. That is, instead of displaying the data as it is reported in the literature with the formation of product [B] vs. time, the data is displayed and fit as the loss of reactant [A] vs. time. These two display modes are of course equivalent so long a mass balance, $[\mathrm{A}]_{\mathrm{o}}=[\mathrm{A}]_{\mathrm{t}}+[\mathrm{B}]_{\mathrm{t}}$ are obeyed throughout the reaction, see equations 2 and 3 of the main text.

Numerical integration curve fitting for the 2-, 3-, and 4-step mechanisms was accomplished with MacKinetics (version 0.9.1b) as detailed in our previous publications (vi,ix) in order to compare the residual values from the fits to each of the three mechanisms. The MacKinetics freeware used for numerical integration was downloaded at http://members.dca.net/leipold/mk/advert.html. The availability and support of MacKinetics has become problematic in the time since we first obtained MacKinetics, however. Hence, we have listed elsewhere (ix) the available numerical integration curve- 
fitting software we can locate, and also recommend interested readers to take a look at the freeware Copasi available at http://www.copasi.org. Table S2 contains the rate constants obtained for each of the kinetic data sets fit in Figures S4-S7.

(a)

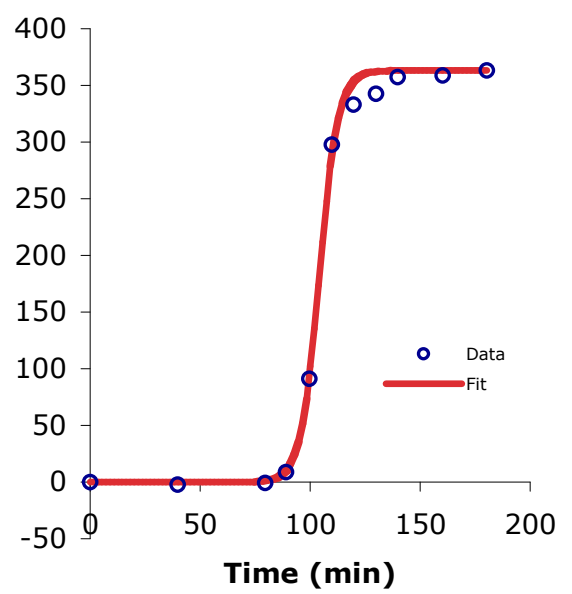

(b)

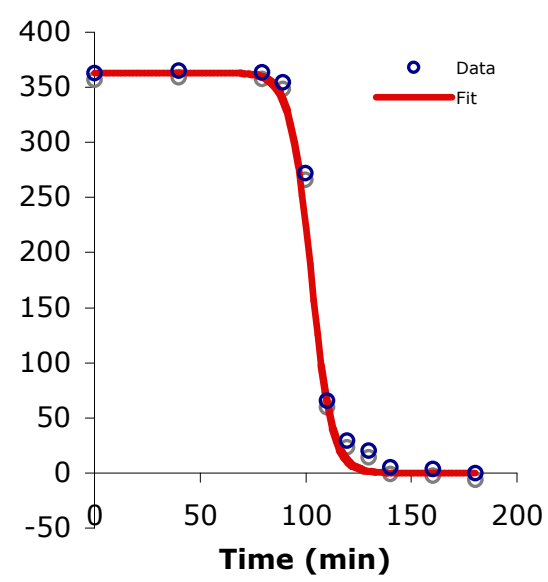

Figure S3. An example of plotting the aggregation data as (a) the formation of [B] vs. time, and (b) the loss of [A] vs. time. In both cases the rate constants obtained are identical with $\mathrm{k}_{1}=1(3) \times 10^{-11}$ and $\mathrm{k}_{2}=6(1) \times 10^{-4}$ as required since the data were interconverted via subtraction of the maximal intensity from each data point. As expected, the $\mathrm{R}^{2}$ values are also equivalent, 0.9968 and $\mathrm{R}^{2}=0.9968$ for the curves (a) and (b), respectively.

Alternative Mechanisms Considered: the 3-and 4-Step Mechanisms. The 3- and 4-step mechanisms (vi,viii,ix) of nanocluster formation and subsequent agglomeration are shown in Schemes S5 and S6. The 4-step mechanism is a relatively rare example of a mechanism with two autocatalytic steps as discussed further elsewhere (viii,ix). 
Scheme S5. The 3-step mechanism for transition-metal nanocluster formation and bimolecular agglomeration (vi).

$$
\begin{aligned}
& A \stackrel{k_{1}}{\longrightarrow} B \\
& A+B \stackrel{k_{2}}{\longrightarrow} 2 B \\
& B+B \stackrel{k_{3}}{\longrightarrow} C
\end{aligned}
$$

Scheme S6. The 4-step mechanism for nanocluster formation that involves two autocatalytic steps (viii).

$$
\begin{aligned}
& A \stackrel{k_{1} \longrightarrow}{\longrightarrow} B \\
& A+B \stackrel{k_{2}}{\longrightarrow} 2 B \\
& B+B \stackrel{k_{3}}{\longrightarrow} C \\
& B+C \stackrel{k_{4}}{\longrightarrow} 1.5 C
\end{aligned}
$$

Since we only disprove in science in general and in mechanism in particular, it was important to see if the 3- or 4-step mechanism might be able to provide superior fits to kinetic data that were less then very well fit by the 2-step F-W mechanism. Figures S4-S7 below reveal that three of the data sets originally in Figures 2-12 of the main text can also be fit by the 3- or 4-step mechanisms. However, by comparison of the residual values for the 2-, 3-, and 4-step mechanisms, Table S2, and in line with a conditional exclusion by Ockham's razor (xvi) of the more complicated mechanisms in the absence of compelling evidence for those more complex mechanisms, the simpler 2-step F-W model was used to analyze the data below and as shown in Figures 2-12 of the main text. 
(a)

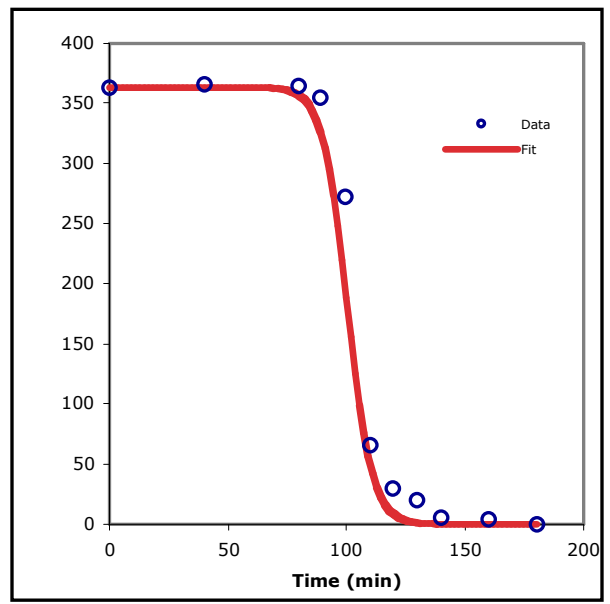

(b)

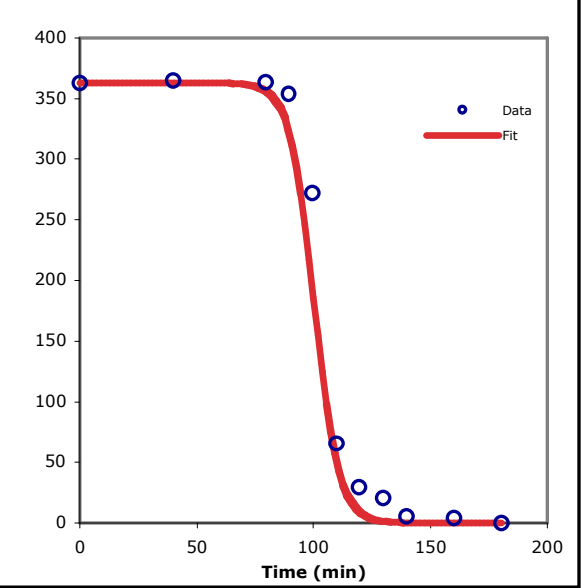

Figure S4. Goto and coworkers' (xvii) digitized data for the ultrasonification-induced aggregation of $\beta 2$-microglobulin monitored by ThT fluorescence and fit to the (a) 3-step and (b) 4-step mechanisms developed by the Finke group.

(a)

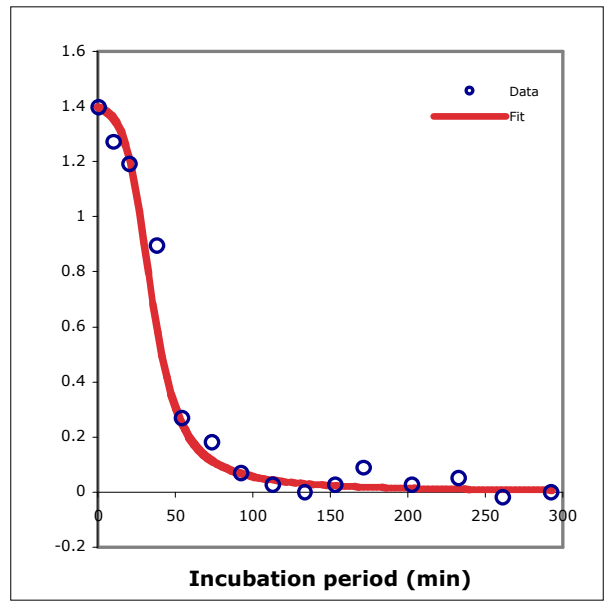

(b)

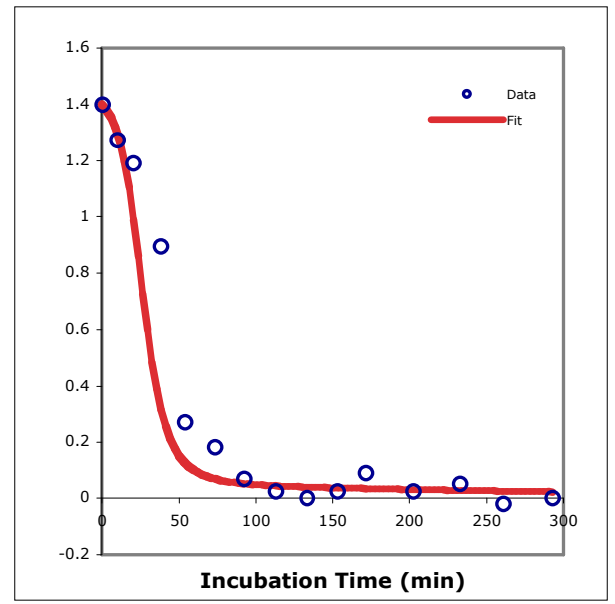

Figure S5. Vestergaard et al's (xviii) amyloid $\beta$ (A $\beta-40)$ peptide measured ThT fluorescence and fit to the (a) 3-step and (b) 4-step mechanisms. 
(a)

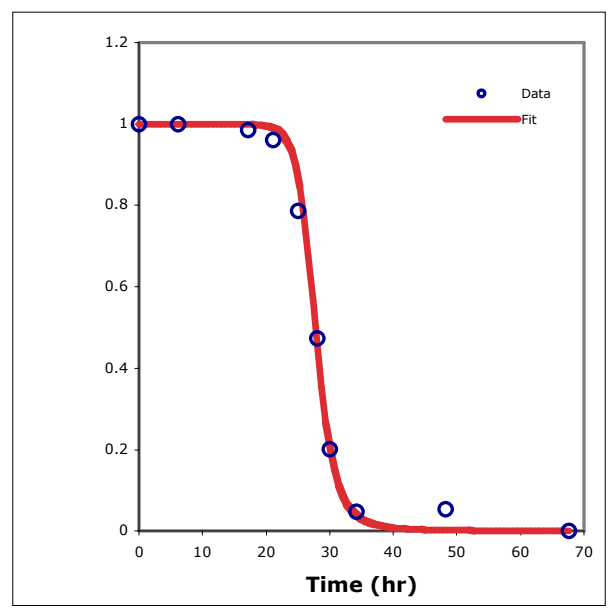

(b)

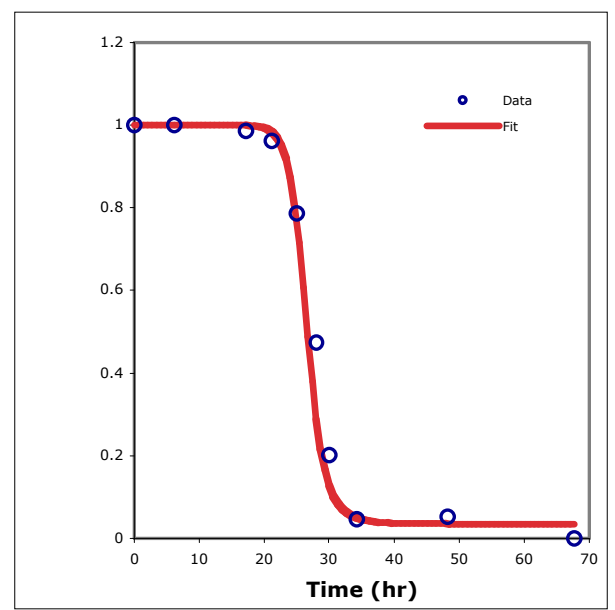

Figure S6. Lynn and coworkers' (xix) amyloid $\beta$ peptide measured by circular dichroism (CD) and fit to the (a) 3-step and (b) 4-step mechanisms.

(a)

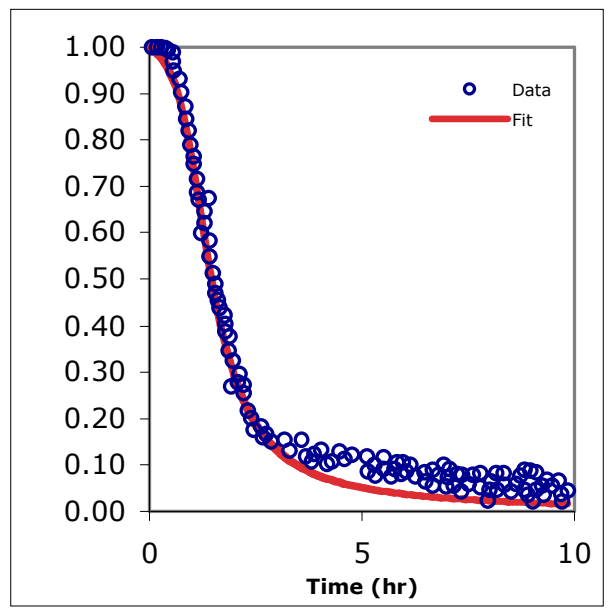

(b)

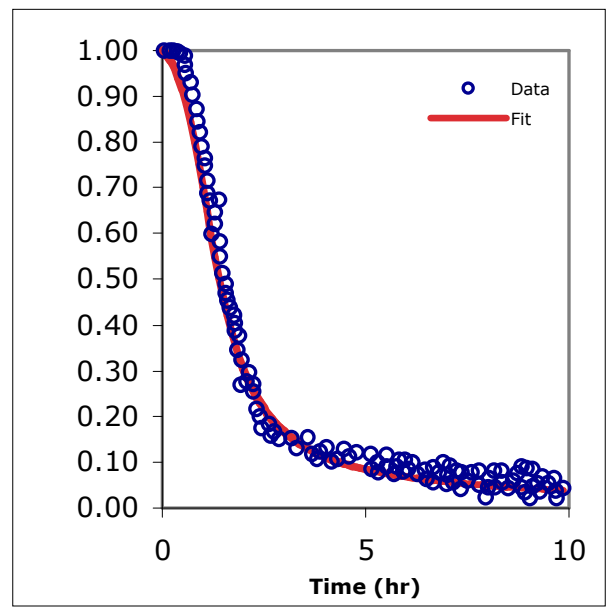

Figure S7. Dobson and coworkers' $(\mathrm{xx})$ in vitro D67H human lysozyme variant fit to the (a) 3-step and (b) 4-step mechanisms.

Figure S7 is better fit to the 3- and 4-step mechanisms for the latter half of the data. However, what is not easily observed here, but is important in choosing the best fit, is the undercutting of the first half of the data seen in the 3-and 4-step fits. This is a case where the 2-step mechanism (Figure 12 of the main text) fits better for the first half of the data and the 3- and 4-step mechanisms fit somewhat better for the second half of the data. 
While the 3- and 4-step mechanism appear to fit the second half of the data better (especially in the case of Figure S7; see Figure 12 of the main text for the 2-step fit), the residual values from each of the 2-, 3-, and 4-step fits show little difference, entry 4 of Table S2. Moreover, the the $\mathrm{k}_{1}$ and $\mathrm{k}_{2}$ values for the 2-, 3-, and 4-step mechanisms are similar in each case (entries 1-4 of Table S2). Hence, again we chose the simplest, Ockham's razor (xvi) 2-step mechanism to fit the data reported in the main text.

Table S2. Comparison of residual values obtained from the 2-, 3-, and 4-step mechanistic fits to the data presented in Figures S4-S7.

\begin{tabular}{|c|c|c|c|c|c|c|}
\hline Entry & Reference & System & & 2-Step Fit & 3-Step Fit & 4-Step Fit \\
\hline \multirow[t]{5}{*}{1} & Goto (xvii) & $\beta$-microglobulin & $\mathrm{k}_{1}$ & $2.5 \times 10^{-10}$ & $7.7 \times 10^{-10}$ & $1.0 \times 10^{-9}$ \\
\hline & & & $\mathrm{k}_{2}$ & $5.5 \times 10^{-4}$ & $5.3 \times 10^{-4}$ & $5.2 \times 10^{-4}$ \\
\hline & & & $\mathrm{k}_{3}$ & & $8.3 \times 10^{-10}$ & $1.5 \times 10^{-9}$ \\
\hline & & & $\mathrm{k}_{4}$ & & & $1.0 \times 10^{-10}$ \\
\hline & & & Residual & 0.03497 & 0.05691 & 0.05771 \\
\hline \multirow[t]{5}{*}{2} & Vestergaard & Amyloid- $\beta$ & $\mathrm{k}_{1}$ & $7.0 \times 10^{-3}$ & $1.3 \times 10^{-3}$ & $3.3 \times 10^{-3}$ \\
\hline & & & $\mathrm{k}_{2}$ & $3.4 \times 10^{-2}$ & $1.0 \times 10^{-1}$ & $1.0 \times 10^{-1}$ \\
\hline & & & $\mathrm{k}_{3}$ & & $4.9 \times 10^{-2}$ & $2.3 \times 10^{-2}$ \\
\hline & & & $\mathrm{k}_{4}$ & & & $8.3 \times 10^{-2}$ \\
\hline & & & Residual & 0.06901 & 0.05689 & 0.1116 \\
\hline \multirow[t]{5}{*}{3} & Lynn (xix) & Amyloid- $\beta$ & $\mathrm{k}_{1}$ & $7.5 \times 10^{-10}$ & $1.1 \times 10^{-9}$ & $1.1 \times 10^{-9}$ \\
\hline & & & $\mathrm{k}_{2}$ & $7.5 \times 10^{-1}$ & $7.3 \times 10^{-1}$ & $7.6 \times 10^{-1}$ \\
\hline & & & $\mathrm{k}_{3}$ & & $1.1 \times 10^{-1}$ & $1.1 \times 10^{-1}$ \\
\hline & & & $\mathrm{k}_{4}$ & & & $8.2 \times 10^{-1}$ \\
\hline & & & Residual & 0.02117 & 0.02735 & 0.08707 \\
\hline \multirow[t]{5}{*}{4} & Dobson (xx) & D67H lysozyme & $\mathrm{k}_{1}$ & $1.1 \times 10^{-1}$ & $4.9 \times 10^{-2}$ & $8.5 \times 10^{-2}$ \\
\hline & & & $\mathrm{k}_{2}$ & 1.8 & 3.2 & 3.0 \\
\hline & & & $\mathrm{k}_{3}$ & & 2.4 & 2.7 \\
\hline & & & $\mathrm{k}_{4}$ & & & 1.1 \\
\hline & & & Residual & 0.08148 & 0.07403 & 0.11009 \\
\hline
\end{tabular}

Fitting Seeded Protein Aggregation Data. Some of the protein aggregation kinetic data that we found in the literature relevant to neurodegenerative diseases is for seeded protein agglomeration. Those data were digitized with Engauge Digitizer 2.12 and fit using Origin 7.0. Each data set was then fit (i) as a control to the original F-W 2- 
step mechanism, which assumes an initial concentration of $B=0$, via equations (1) or (2) of the main text, and then also (ii) to the analytical equation shown below in equation (S1) or (S2), depending upon the way the data was reported in the literature, S1 and S2 being the equations for the F-W 2-step mechanism, but with $[\mathrm{B}]_{0} \neq 0$ (i.e., for the seeded case). The data sets were also fit (iii) by a hypothetical mechanism of autocatalysis alone, namely just the $\mathrm{A}+\mathrm{B} \rightarrow 2 \mathrm{~B}$ step, equations (S3) and (S4). The derivation of equations (S1) and (S2) is shown below in Scheme S7. The derivation of equations (S3) and (S4) can be found in several textbooks, for example reference (xxi).

$[A]_{t}=\frac{\left(k_{1}+k_{2}\left([A]_{0}+[B]_{0}\right)\right)[A]_{0}}{k_{2}[A]_{0}+k_{1} e^{\left(k_{1}+k_{2}\left([A]_{0}+[B]_{0}\right)\right) t}}$

$[B]_{t}=\left([A]_{0}-[B]_{0}\right)-\frac{\left(k_{1}+k_{2}\left([A]_{0}+[B]_{0}\right)\right)[A]_{0}}{k_{2}[A]_{0}+k_{1} e^{\left(k_{1}+k_{2}\left([A]_{0}+[B]_{0}\right)\right) t}}$

$[A]_{t}=\left([A]_{0}+[B]_{0}\right)-\frac{[A]_{0}+[B]_{0}}{1+\frac{[A]_{0}}{[B]_{0}} e^{-k\left([A]_{0}+[B]_{0}\right) t}}$

$[B]_{t}=\frac{[A]_{0}+[B]_{0}}{1+\frac{[A]_{0}}{[B]_{0}} e^{-k\left([A]_{0}+[B]_{0}\right) t}}$ 
Scheme S7. Derivation of the 2-step mechanism with $[\mathrm{B}]_{0} \neq 0$.

$-\frac{d[A]}{d t}=k_{1}[A]+k_{2}[A][B]$

By mass balance and assuming that $[\mathrm{B}]_{0} \neq 0$ :

$[B]=[B]_{0}+[A]_{0}-[A]$

$-\frac{d[A]}{d t}=k_{1}[A]+k_{2}[A]\left([B]_{0}+[A]_{0}-[A]\right)$

$\int_{0}^{t} \frac{-d[A]}{k_{1}[A]+k_{2}[A]\left([B]_{0}+[A]_{0}-[A]\right)}=\int d t$

$\left.\frac{1}{k_{1}+k_{2}\left([A]_{0}+[B]_{0}\right)} \ln \left(\frac{k_{1}+k_{2}\left([A]_{0}+[B]_{0}-[A]\right)}{[A]}\right)\right]_{0}^{t}=t$

$\ln \left(\frac{\left(k_{1}+k_{2}\left([A]_{0}+[B]_{0}-[A]\right)\right)[A]}{k_{1}[A]}\right)=\left(k_{1}+k_{2}\left([A]_{0}+[B]_{0}\right)\right) t$

$\frac{\left(k_{1}+k_{2}\left([A]_{0}+[B]_{0}-[A]\right)\right)[A]}{k_{1}[A]}=e^{\left(k_{1}+k_{2}\left([A]_{0}+[B]_{0}\right)\right) t}$

$[A]_{t}=\frac{\left(k_{1}+k_{2}\left([A]_{0}+[B]_{0}\right)\right)[A]_{0}}{k_{2}[A]_{0}+k_{1} e^{\left(k_{1}+k_{2}\left([A]_{0}+[B]_{0}\right)\right) t}}$

Which by mass balance of :

$[\mathrm{A}]_{\mathrm{t}}=[A]_{0}-[B]_{0}-[B]_{t}$

can also be expressed as :

$[\mathrm{B}]_{\mathrm{t}}=[A]_{0}-[B]_{0}-\frac{\left(k_{1}+k_{2}\left([A]_{0}+[B]_{0}\right)\right)[A]_{0}}{k_{2}[A]_{0}+k_{1} e^{\left(k_{1}+k_{2}\left([A]_{0}+[B]_{0}\right)\right) t}}$

The data and fits shown below in Figure S8 correspond to the data found in

Figure 10 of the main text for the unseeded case. What is observed in Figure S8 is that each of the proposed mechanisms seems to fit the seeded aggregation kinetic data, but by examination of the $\mathrm{R}^{2}$ values in Table $\mathrm{S} 2$, the 2 -step mechanism with $[\mathrm{B}]_{0} \neq 0$ provides the best overall fit. 


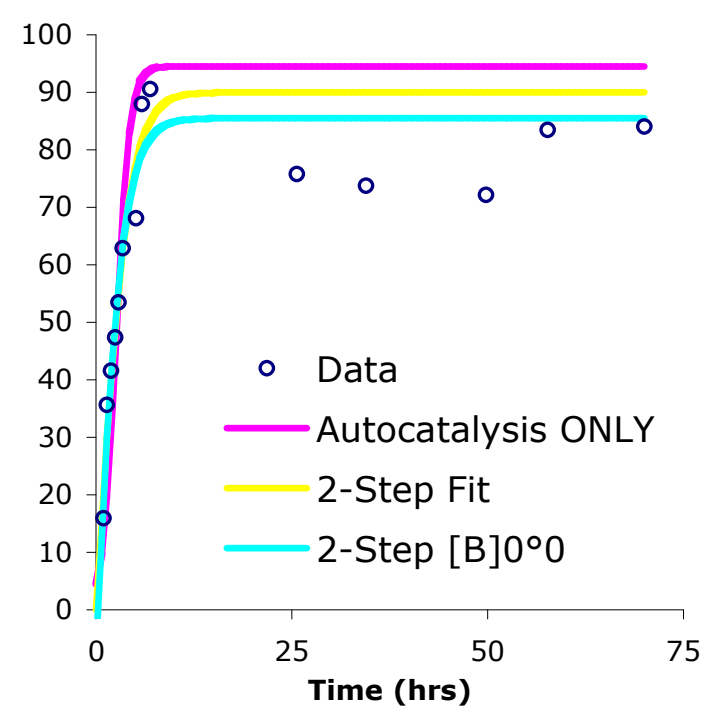

Figure S8. Wetzel's (xxii) seeded protein aggregation kinetic data measured by dynamic light scattering and fit to autocatalysis only (pink), the F-W 2-step mechanism (yellow), and the 2-step mechanism with $[\mathrm{B}]_{0} \neq 0$ (teal).

Table S3. Rate constants and $\mathrm{R}^{2}$ values obtained for the data in shown in Figure S8

\begin{tabular}{lrr}
\hline Autocatalysis only & $\mathrm{k}=1.2(1) \times 10^{-2} \mathrm{hr}^{-1}$ & $\mathrm{R}^{2}=0.75718$ \\
Classic 2-step mechanism & $\mathrm{k}_{1}=2.3(9) \times 10^{-1} \mathrm{hr}^{-1}$ & $\mathrm{R}^{2}=0.89385$ \\
& $\mathrm{k}_{2}=3(3) \times 10^{-3} \mu \mathrm{M}^{-1} \mathrm{hr}^{-1}$ & \\
2-step mechanism with $[\mathrm{B}]_{0} \neq 0$ & $\mathrm{k}_{1}=2.9(8) \times 10^{-1} \mathrm{hr}^{-1}$ & $\mathrm{R}^{2}=0.92885$ \\
& $\mathrm{k}_{2}=3(3) \times 10^{-3} \mu \mathrm{M}^{-1} \mathrm{hr}^{-}$ & \\
& & \\
\end{tabular}

A second set of seeded protein aggregation kinetic data was also fit. Note, in the original publication (xxiii) the absorbance data does not reach zero. Therefore, it was assumed the that residual absorbance observed is some sort of background absorbance and, hence, that the data should be corrected by subtracting the difference between the last leveled off data points and zero in the cases of $0.01,0.1,1$, and $10 \%$ seeded cases. (The data could not be corrected in the case of $0.001 \%$ seeded because there is no final leveling off point present, i.e., the growth phase is not completely shown in the original paper (xxiii).) Both the raw data and corrected data were analyzed by both the 2-step 
mechanism and the 2-step mechanism with $[\mathrm{B}]_{0} \neq 0$; the results can be seen in Table $\mathrm{S} 4$.

The corrected data gives the better fit and can be seen in Figure S9.

(a)

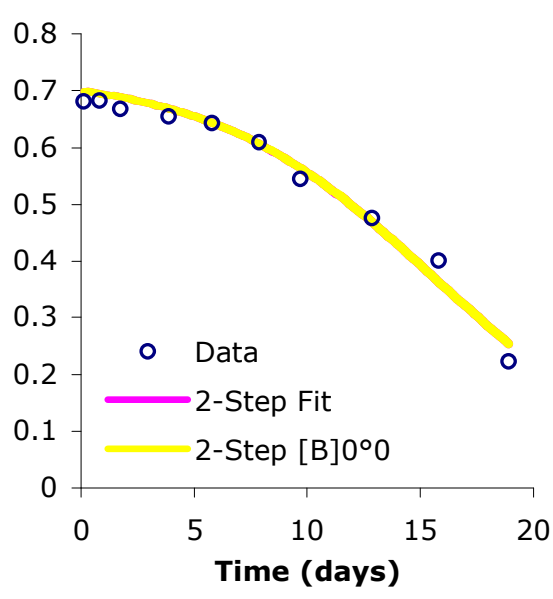

(d)

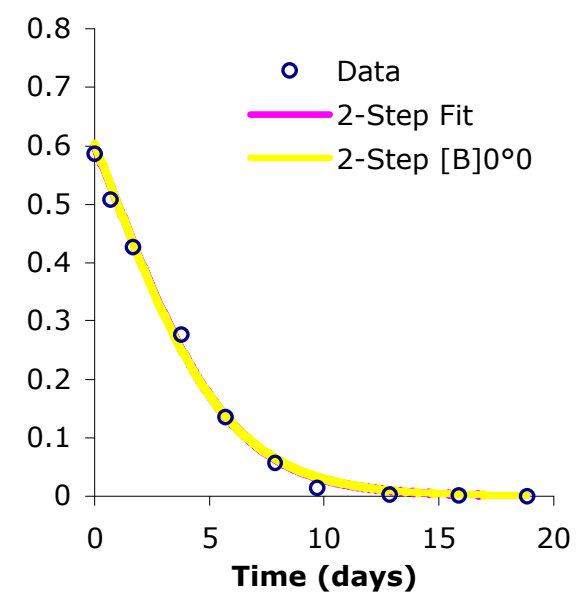

(c)
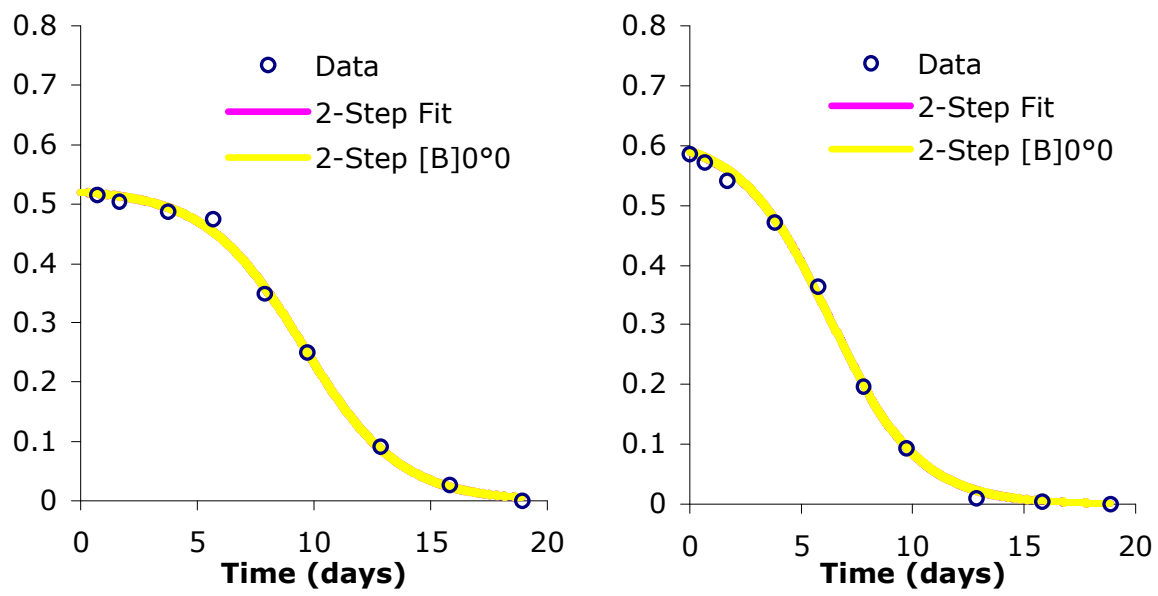

(e)

Figure S9. Biere's (xxiii) (a) $0.001 \%$, (b) $0.01 \%$, (c) $0.1 \%$, (d) $1 \%$, and (e) $10 \%$ seeded $\alpha$-synuclein data after correction for the non-zero residual absorbance and curve-fit to the F-W 2-step mechanism (as a control) and then to the 2-step mechanism with $[\mathrm{B}]_{0} \neq 0$.

Both the 2-step mechanism and the 2-step mechanism with $[\mathrm{B}]_{0} \neq 0$ give the same rate constants within experimental error for the seeded data with $\leq 0.1 \%$ seed. However, the baseline-corrected data with a seed concentration $>0.1 \%$ is better fit by the 2 -step mechanism with $[\mathrm{B}]_{0} \neq 0$. (When the uncorrected data were analyzed, negative rate 
constants were obtained for both the cases of $1 \%$ and $10 \%$ seeded shown in Table S4.)

The 2-step mechanism with $[\mathrm{B}]_{0} \neq 0$ is not able to account for the data at higher seed concentrations; our belief is that the mechanism may change to a presently unknown mechanism at seed concentrations at or above certain concentration levels.

Table S4. The rate constants, $\mathrm{k}_{1}$ and $\mathrm{k}_{2}$, obtained from the uncorrected data as originally published (xxiii) and the corrected data shown in Figure S9.

\begin{tabular}{|c|c|c|c|c|c|}
\hline$\%$ Seeded & Fit & Corrected? & $\mathrm{k}_{1}$ (days $\left.^{-1}\right)$ & $\mathrm{k}_{2}\left(\mu \mathrm{M}^{-1}\right.$ days $\left.^{-1}\right)$ & $\mathrm{R}^{2}$ \\
\hline \multirow[t]{2}{*}{$\overline{0.001}$} & 2-step & No & $8(2) \times 10^{-3}$ & $2.8(3) \times 10^{-1}$ & 0.98115 \\
\hline & 2 -step $+[\mathrm{B}]_{0} \neq 0$ & No & $8(2) \times 10^{-3}$ & $2.8(3) \times 10^{-1}$ & 0.98115 \\
\hline \multirow[t]{4}{*}{$\overline{0.01}$} & 2-step & No & $1.6(4) \times 10^{-2}$ & $3.0(5) \times 10^{-1}$ & 0.97507 \\
\hline & & Yes & $4.8(9) \times 10^{-3}$ & $9.2(5) \times 10^{-1}$ & 0.99808 \\
\hline & 2 -step $+[\mathrm{B}]_{0} \neq 0$ & No & $1.6(4) \times 10^{-2}$ & $3.0(5) \times 10^{-1}$ & 0.97508 \\
\hline & & Yes & $4.8(9) \times 10^{-3}$ & $9.2(5) \times 10^{-1}$ & 0.99808 \\
\hline \multirow[t]{4}{*}{$\overline{0.1}$} & 2-step & No & $5(1) \times 10^{-2}$ & $2.7(8) \times 10^{-1}$ & 0.97505 \\
\hline & & Yes & $2.1(3) \times 10^{-2}$ & $8.1(5) \times 10^{-1}$ & 0.99849 \\
\hline & 2 -step $+[\mathrm{B}]_{0} \neq 0$ & No & $5(1) \times 10^{-2}$ & $2.7(8) \times 10^{-1}$ & 0.97514 \\
\hline & & Yes & $2.1(3) \times 10^{-2}$ & $8.1(5) \times 10^{-1}$ & 0.99843 \\
\hline \multirow[t]{4}{*}{1} & 2-step & No & $2.2(3) \times 10^{-1}$ & $-1.8(9) \times 10^{-1}$ & 0.98231 \\
\hline & & Yes & $1.6(2) \times 10^{-1}$ & $4(1) \times 10^{-1}$ & 0.99590 \\
\hline & 2 -step $+[\mathrm{B}]_{0} \neq 0$ & No & $3.6(5) \times 10^{-1}$ & $-5.7(8) \times 10^{-1}$ & 0.95212 \\
\hline & & Yes & $1.6(2) \times 10^{-1}$ & $4(1) \times 10^{-1}$ & 0.99538 \\
\hline \multirow[t]{4}{*}{$\overline{10}$} & 2-step & No & $3.0(8)$ & $-5(1)$ & 0.94538 \\
\hline & & Yes & $2(20,000) \times 10^{-6 a}$ & $50(300,000)^{a}$ & 0.99177 \\
\hline & 2 -step $+[\mathrm{B}]_{0} \neq$ & No & $9.9(7)$ & $-15(1)$ & 0.99105 \\
\hline & & Yes & $1.0(3)$ & $6(2)$ & 0.99196 \\
\hline
\end{tabular}

${ }^{\mathrm{a}}$ These resulting errors that were 100-1000 times larger than the actual rate constants indicates the inability of the mechanism to account for the data.

The rate constants obtained from the fits to the corrected absorbance data (as displayed in the five graphs in Figure S9) were plotted as a function of the added seed in Figure $\mathrm{S} 10$. The $\mathrm{k}_{1}$ dependence on the concentration of $\mathrm{B}_{0}$ is first-order (i.e., if we did not need the logarithmic scale in $\mathrm{x}$-axis of Figure S10a to display the data in the space allowed, then a linear $\mathrm{k}_{1}$ vs concentration plot would be apparent). The $\mathrm{k}_{2}$ dependence on 
added seed does not show any discernable dependence of the concentration of added seed, $\mathrm{B}_{0}$.

(a)

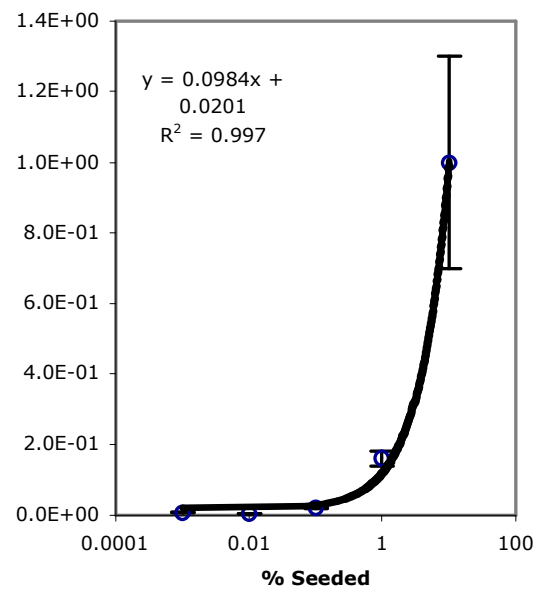

(b)

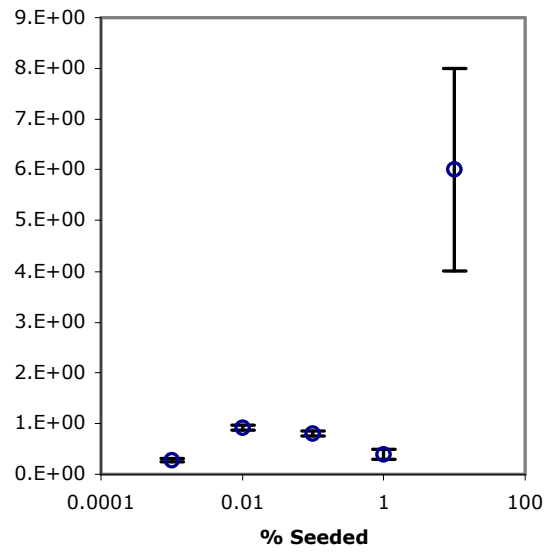

Figure S10. (a) $\mathrm{k}_{1}$ and (b) $\mathrm{k}_{2}$ correlations with the concentration of added seed for the corrected $\alpha$-synuclein aggregation data from ref (xxiii). Note the logarithmic x-axis in each graph.

Our current working hypothesis as far as the seeded kinetic data sets go is that the 2-step mechanism is able to account for the data up to a certain level of seed concentration after which it appears that the aggregation mechanism may be changing to some at present, unknown pathway. Obviously, further studies of seeded protein aggregation will be needed before definitive statements about the underlying mechanism(s) can be made. 


\section{References for the Mathematical Derivations:}

${ }^{\text {i } W a t z k y, ~ M . ~ A ., ~ a n d ~ F i n k e, ~ R . ~ G . ~(1997) ~ T r a n s i t i o n ~ m e t a l ~ n a n o c l u s t e r ~ f o r m a t i o n ~ k i n e t i c ~}$ and mechanistic studies. A new mechanism when hydrogen is the reductant: slow, continuous nucleation and fast autocatalytic surface growth, J. Am. Chem. Soc. 119, 10382-10400.

${ }^{\text {ii }}$ Kamihira, M., Naito, A., Tuzi, S., Nosaka, A. Y., and Saitô, H. (2000) Conformational transitions and fibrillation mechanism of human calcitonin as studied by high-resolution solid-state ${ }^{13}$ C NMR, Protein Science 9, 867-877.

${ }^{\text {iii }}$ Uversky, V. N., Li, J., and Fink, A. L. (2001) Evidence for a partially folded intermediate in $\alpha$-synuclein fibril formation, J. Biol. Chem. 276, 10737-10744.

${ }^{\text {iv }}$ DuBay, K. F., Pawar, A. P., Chiti, F., Zurdo, J., Dobson, C. M., and Venruscolo, M. (2004) Prediction of the absolute aggregation rates of amyloidogenic polypeptide chains, J. Mol. Biol. 341, 1317-1326.

\section{References for Nanocluster Studies:}

${ }^{v}$ Aiken III, J. D., and Finke, R. G. (1998) Nanocluster Formation Synthetic, Kinetic, and Mechanistic Studies. The Detection of, and Then Methods To Avoid, Hydrogen MassTransfer Limitations in the Synthesis of Polyoxoanion- and TetrabutylammoniumStabilized, Near-Monodisperse $40 \pm 6 \AA$ Rh(0) Nanoclusters, J. Am. Chem. Soc. 120, 9545-9554.

vi Widegren, J. A.; Aiken III, J. D., Özkar, S., and Finke, R. G. (2001) Additional Investigations of a New Kinetic Method To Follow Transition-Metal Nanocluster Formation, Including the Discovery of Heterolytic Hydrogen Activation in Nanocluster Nucleation Reactions, Chem. Mater. 13, 312-324.

${ }^{\text {vii }}$ Hornstein, B. J., and Finke, R. G. (2004) Transition-Metal Nanocluster Kinetic and Mechanistic Studies Emphasizing Nanocluster Agglomeration: Demonstration of a Kinetic Method That Allows Monitoring of All Three Phases of Nanocluster Formation and Aging, Chem. Mater. 16, 139-150. See also correction Hornstein, B. J., and Finke, R. G. (2004) Chem. Mater. 16, 3972-3972.

viii Besson, C., Finney, E. E., and Finke, R. G. (2005) A Mechanism for Transition-Metal Nanoparticle Self-Assembly, J. Am. Chem. Soc. 127, 8179-8184.

${ }^{i x}$ Besson, C., Finney, E. E., and Finke, R. G. (2005) Nanocluster Nucleation, Growth, and Then Agglomeration Kinetic and Mechanistic Studies: A More General, Four-Step Mechanism Involving Double Autocatalysis, Chem. Mater. 17, 4925-4938.

\section{References for Protein Intermediate Protofibrils/Soluble Oligomers:}

${ }^{\mathrm{x}}$ Walsh, D.M., Lomakin, A., Benedek, G.B., Condron, M.M., and Teplow, D.B. (1997) Amyloid $\beta$-protein fibrillogenesis: Detection of a protofibrillar intermediate, J. Biol. Chem. 272, 22364-22372.

${ }^{\mathrm{xi}}$ Walsh, D.M., Hartley, D.M., Kusumoto, Y., Fezoui, Y., Condron, M.M., Lomakin, A., Benedek, G.B., Selkoe, D.J., and Teplow, D.B. (1999) Amyloid $\beta$-protein fibrillogenesis: 
Structure and biological activity of protofibrillar intermediates, J. Biol. Chem. 274, 25945-25952.

xii Harper, J.D., Wong, S.S., Lieber, C.M., and Lansbury Jr., P.T. (1997) Observation of metastable A $\beta$ amyloid protofibrils by atomic force microscopy, Chem. Biol. 4, 199-125. xiii Volles, M.J., Lee, S.-J., Rochet, J.-C., Shtilerman, M.D., Ding, T.T., Kessler, J.C., and Lansbury Jr., P.T. (2001) Vesicle permeabilization by protofibrillar $\alpha$-synuclein. Implications for the pathogenesis and treatment of Parkinson's disease, Biochem. 40, 7812-7819.

xiv Lambert, M.P. Barlow, A.K., Chromy, B.A., Edwards, C., Freed, R., Liosatos, M., Morgan, T.E., Rozovsky, I., Trommer, B., Viola, K.L., Wals, P., Zhang, C., Finch, C.E., Krafft, G.A., and Klein, W.L. (1998) Diffusible, nonfibrillar ligands derived from A $\beta(1-$ 42) are potent central nervous system neurotoxins, Proc. Natl. Acad. Sci. USA 95, 64486453.

\section{Other References for the Supporting Information:}

${ }^{x v}$ Dong, J., Shokes, J. E., Scott, R. A., and Lynn, D. G. (2006) Modulating amyloid selfassembly and fibril morphology with Zn(II), J. Am. Chem. Soc. 128, 3540-3542.

${ }^{x v i}$ William of Ockham, 1285-1349, as cited by E. A. Moody (1967) in The Encyclopedia of Philosophy, vol 7, MacMillan, New York.

xvii Ban, T., Yamaguchi, K., and Goto, Y. (2006) Direct observation of amyloid fibril growth, propagation, and adaptation, Acc. Chem. Res. 39, 663-670.

xviii Vestergaard, M., Kerman, K., Saito, M., Nagatani, N., Takamura, Y., and Tamiya, E. (2005) A rapid label-free electrochemical detection and kinetic study of Alzheimer's amyloid beta aggregation, J. Am. Chem. Soc. 127, 11892-11893.

${ }^{x i x}$ Lu, K., Jacob, J., Thiyagarajan, P., Conticello, V. P., and Lynn, D. G. (2003) Exploiting amyloid fibril lamination for nanotube self-assembly, J. Am. Chem. Soc. 125, 6391-6393.

${ }^{x x}$ Dumoulin, M., Kumita, J. R., and Dobson, C. M. (2006) Normal and aberrant biological self-assembly: Insights from studies of human lysozyme and its amyloidogenic variants, Acc. Chem. Res. 39, 603-610.

${ }^{x x i}$ Steinfeld, J. I.; Francisco, J. S.; Hase, W. L. (1989) Autocatalysis and oscillating reactions, in Chemical Kinetics and Dynamics, pp 182-183, Prentice-Hall, New Jersey. xxii Wetzel, R. (2006) Kinetics and thermodynamics of amyloid fibril assembly, Acc. Chem. Res. 39, 671-679.

xxiii Wood, S. J.; Wypych, J.; Steavenson, S.; Louis, J.-C.; Citron, M.; Biere, A. L. (1999) $\alpha$-Synuclein fibrillogenesis is nucleation-dependent, J. Biol. Chem. 274, 19509-19512. 